Article

\title{
Comparative Analysis of Hybrid Desalination Technologies Powered by SMR
}

\author{
Seyed Hadi Ghazaie ${ }^{1, *}$, Khashayar Sadeghi ${ }^{1}$, Ekaterina Sokolova ${ }^{1}$, Evgeniy Fedorovich ${ }^{1}$ \\ and Amirsaeed Shirani ${ }^{2}$ \\ 1 Department of Atomic and Heat- and -Power Engineering, \\ Peter the Great St. Petersburg Polytechnic University, St Petersburg 195251, Russia; \\ sadegi.h@edu.spbstu.ru (K.S.); sokolenergo@mail.ru (E.S.); efed1@yandex.ru (E.F.) \\ 2 Faculty of Nuclear Engineering, Shahid Beheshti University of Iran, Tehran 1983963113, Iran; \\ a_shirani@sbu.ac.ir \\ * Correspondence: gazai.sh@edu.spbstu.ru
}

Received: 19 August 2020; Accepted: 23 September 2020; Published: 23 September 2020

check for updates

\begin{abstract}
Small modular reactors (SMRs) represent a key area of interest to nuclear industry developers, which have been making significant progress during the past few years. Generally, these reactors are promising owing to their improved safety due to passive systems, enhanced containment efficiency, and fewer capital costs in comparison to traditional nuclear reactors. An important advantage of SMRs is their adaptability in being coupled to other energy-consuming systems, such as desalination plants (DPs) to create a cogeneration plant. Considering the serious challenges regarding the freshwater shortage in many regions of the world and the necessity of using low-carbon energy sources, it is advantageous to use SMR for supplying the required heat and electricity of DPs. As a high-performance desalination technology, the hybrid desalination (HD) systems can be exploited, which retain the advantages of both thermal and membrane desalination methods. In this study, several SMR coupling schemes to HD plants have been suggested. In performing a thermodynamic analysis of integrated SMR-DP, the International Atomic Energy Agency (IAEA) Desalination Thermodynamic Optimization Program (DE-TOP) has been utilized. It has been found that the use of relatively hot water from the SMR condenser leads to about 6.5 to $7.5 \%$ of total desalination cost reduction, where the produced electricity and hot steam extracted from low-pressure turbine were used to drive the HD system.
\end{abstract}

Keywords: small modular reactor (SMR); seawater desalination; nuclear desalination; hybrid desalination technologies; cogeneration systems; thermo-economic analysis; DE-TOP program

\section{Introduction}

The scale of the problem regarding supplying humanity with freshwater is currently growing throughout the world. The freshwater reserves are large and renewable, but the scale of their consumption exceeds the renewable flows. The situation in the world is such that freshwater resources are extremely unevenly distributed, as a result of which, several regions in the world are experiencing an acute shortage of water resources. The freshwater issue is especially critical in arid regions, where freshwater reserves are limited or do not exist, while the reserves of brackish groundwater and saline waters are remarkably large. In connection with the growing pollution of water resources, population growth, the development of new territories, and the extension of deserts, the task of artificially freshwater production arises, which has become one of the world's most pivotal water treatment solutions. Therefore, the development of technologies for obtaining freshwater from saline waters, and in particular, from seawater, is of great interest and importance [1]. 
Although desalination can be counted as one worthwhile means of freshwater supply, the high energy consumption can be considered its primary disadvantage, which significantly increases the desalination cost [2]. About $47 \%$ of operating expenditure belongs to electrical and thermal energies, which are required in different desalination processes [3]. As an example, the amount of energy required for obtaining one cubic meter of freshwater from seawater (the most energy-intensive water source for desalination) varies from 2.58 to $8.5 \mathrm{kWh} / \mathrm{m}^{3}$ [4]. However, given the amount of energy required for groundwater and brackish water desalination, seawater desalination gives the impression of being the most appropriate solution for freshwater shortage, since it is sufficient to meet the increasing freshwater demand. In this regard, new research and state of the art technologies can progressively lead to less energy consumption and, consequently, can raise the efficiency of various seawater desalination processes.

Desalination technologies are known to be high energy-demanding processes, so determination of the energy source for desalination is significant in terms of exploitation and perspectives. In many countries, especially in the countries of Middle East, where fossil fuel resources are plentifully available, fossil fuels are being used as the main energy sources for desalination purposes, which affect the environment by generating greenhouse gases (GHG). Since desalination plants (DPs) operate permanently (except the routine periods of repair, maintenance, and replacement of equipment), the power plant, which supplies the energy to DP, should be able to continuously provide the required amount of energy. Therefore, the energy source for desalination systems is recommended to be environmentally clean, economically feasible, technically extendable, and strategically acceptable considering the long-term energy plans of the countries [5].

The concept of small modular reactors (SMRs) has been making considerable progress over the past several years, with some reactors and demonstration projects under construction [6]. Almost all of the companies in the nuclear power industry have presented their SMRs, based on the structural features of their already deployed large-scale nuclear reactors, in addition to the other especial SMR designs. The majority of these reactors are water-cooled typical or integral pressurized water reactors, and a number of high-temperature gas-cooled, sodium, and lead alloy cooled fast SMRs are at the stage of research and development [7]. In addition to their small size, the innovative and inimitable properties of SMRs improve the safety margins and reliability of nuclear energy utilization. Ultimately, these characteristics together help the nuclear energy gaining public acceptance in countries and nations that are planning for nuclear power plant (NPP) construction. Modular construction and size, along with the possibility of being coupled to other energy generating systems, can be considered the main SMR characteristics that led to the growth of interest in these types of nuclear reactors.

Small and medium nuclear power reactors are alternative energy generating systems for shifting from fossil fuel-based power plants, which may be installed independently or as modules in a larger complex. However, some countries are planning for decreasing the share of energy (electricity) production by NPPs (mainly large-scale NPPs) and attempting to develop renewable energy-based power plants [8]. The use of renewable energy sources for desalination purposes, which have several unique advantages especially in association with the less environmental impacts, has been vastly proposed and investigated by many authors [9-11]. However, the intermittence and lower intensity in comparison to nonrenewable energy sources make it difficult to utilize renewables as the energy source for large-scale desalination plants, which can be handled by coupling renewables with nuclear or other power plants, to take the advantages of different energy sources [12].

Generally, desalination processes are classified into two main groups of thermal and membrane separation technologies. The most popular thermal desalination systems are multi-stage flash distillation (MSF), multi-effect distillation (MED), mechanical vapor compression (MVC), and thermal vapor compression. MSF technology dominated the world from the 1980s to the 1990s, owing to the high quality of the water produced. MSF desalination systems are very popular in Middle East countries. Desalination technology in a flash boiling unit differs from the use of conventional boiling when water meets a heating surface. Instant boiling installations are performed in multiple stages. 
In a multistage scheme, due to heat recovery and rational recirculation of brine, it is possible to significantly reduce heat consumption. These types of desalination units can distill very salty water (up to $70,000 \mathrm{mg} / \mathrm{L}$ ) to salinity of 5-25 mg/L. MED technology can be considered the oldest existing desalination technology. In MED desalination units, evaporation occurs in a series of chambers, with a progressive decrease in pressure and temperature. Inside each chamber, desalinated water is injected (supplied) to the surface of the bundle of heat exchange tubes, and heating steam passes inside the tubes and condenses. On the outer surface of the tubes, a thin film of seawater absorbs the heat of the steam and boils. The heating and evaporation of water in the first stage is carried out by the hot stream of the power plant. The heating steam of the next stage is the secondary steam of the previous evaporation chamber. The process is repeated along the entire stages of the MED unit. High efficiency of the process is achieved due to the high intensity of heat transfer in a thin layer of heated liquid and short contact time with heat transfer surface, low energy consumption for the process, as well as the low temperature of the driving steam. Among commercial membrane-based desalination technologies, the most common seawater desalination process is performed through reverse osmosis (RO) technology. The RO process can be described as follows. Semi-permeable membranes have small pores that are capable of passing only water molecules and retaining dissolved solutes with different concentrations. Water molecules move through the membrane from a less concentrated solution to a more concentrated one, due to the applied pressure to the membrane, which overcomes the osmotic pressure. In RO systems, depending on the number of pre-filters and post-filters, various stages are used. Except for MVC, all of the stated thermal desalination processes require electricity and thermal energy (mainly in the form of low-temperature heat) to operate, whereas only electricity is required to drive the high-pressure pumps of $\mathrm{RO}$ unit [5]. In addition to the standalone thermal or membrane desalination technologies, two or more desalination processes can be coupled, which is called a hybrid desalination (HD) technique. Utilization of HD makes it possible to take advantage of both the thermal and membrane desalination processes [13].

Feasibility analyses and technical and economic assessments of using nuclear energy for supplying desalination systems have been carried out in several articles in the literature. A feasibility analysis of nuclear desalination to meet the growing demand for freshwater was performed in 2007, where the main challenge for large-scale desalination and some social and economic factors was discussed [14]. As a case study, the utilization of an SMR heat-only plant coupled with a thermal desalination system in the UAE was carried out, in which the performance and economic evaluation expressed the high capability of the integrated system to help solving the freshwater problem, assuring the safety factors [15]. In 2017, a techno-economic analysis of deploying SMRs integrated into desalination systems in the Middle East and North Africa (MENA) region was conducted [16]. In 2019, a state of the art research in association with the nuclear desalination was performed, in which the latest advances and developments of nuclear desalination were reviewed, and it was stated that SMRs are promising in terms of driving large-scale desalination plants [17]. In 2015, the implementation of a high-temperature gas-cooled pebble-bed reactor (HTR-PM) with the power of $210 \mathrm{MW}_{\mathrm{e}}$ for supplying the required energy of different desalination approaches in the UAE has been evaluated [18]. It was concluded that the use of the HTR-PM reactor as an alternative to fossil fuel-based plants reduces the $\mathrm{CO}_{2}$ emissions and increases the production capacity of desalinated water. A comprehensive techno-economic analysis of the hybrid desalination technologies integrated into a VVER type nuclear reactor was carried out in 2020, in which a new economic calculation algorithm was introduced to evaluate several hybrid desalination processes [5]. Other related previously published research is addressed elsewhere [19-26].

The main purpose of the present study is to perform an in-depth thermo-economic assessment of coupling an SMR with different hybrid desalination technologies, to determine the most favorable configuration. In this regard, several appropriate schemes for coupling HD technologies to the SMR were suggested. To perform the thermodynamic analysis, the well-known computer program Desalination Thermodynamic Optimization Program (DE-TOP) was used, which was developed by 
the International Atomic Energy Agency (IAEA) [27]. The program is capable of analyzing different integration schemes to compare the advantages and drawbacks of each case. As a tool for economic assessment, the newly introduced algorithm and developed software, Techno-Economic Analysis of Nuclear Desalination (TEAND), was utilized in the previous study [5]. While the previously published articles by authors $[5,12,13,19,20]$ provide results of technical and economic analyses of large-scale nuclear-powered desalination systems, the present article focuses on a comprehensive thermo-economic assessment of the SMR integration to the hybrid large-scale desalination plant.

\section{SMR for Supplying the Required Energy for Desalination}

A simple definition for SMR is given by IAEA, which is considered the newer generation of nuclear reactors with the electricity output up to $300 \mathrm{MW}$. This factor makes it possible to assemble the main parts and equipment in factories, and dispatch them to the destination country if demand increases [16]. SMRs are deliberately designed to be small, to provide the operational possibility of several reactors as modules, which yield some innovative features and specific performance characteristics. Currently, there are many proposed SMR designs at different levels of development and construction, which are detailed in $[7,28,29]$. Some of the most famous SMRs are classified by their power output in Table 1. The extremely high capital cost of the typical large-scale NPP has been a significant disadvantage of them. This drawback may be counted as one of the main problems of NPP construction in countries where it is difficult to invest billions of dollars in developing the nuclear sector. Although the new generation of large-scale reactors offer innovative and forward-thinking technology, the following advantages of SMRs can be counted as the main reasons for justification of a global effort for SMR development $[6,7,30,31]$ :

1. Modularity: the possibility of modules factory fabrication removes the complexities from on-site assembly and a number of modules can be added to meet the required amount of heat and/or electricity.

2. Lower capital investment: the smaller size of SMRs and lower construction time in comparison to a typical large-scale reactor leads to a decrease in capital cost.

3. Extra safety: small reactors are more capable of using natural convection, passive safety systems, and other innovative safety technologies.

4. Siting adaptability: the lower amount of demanding infrastructure and smaller footprint provide the possibility of installation on available fossil fuel-based power plant sites nearer habitation, or in the sites with space limitations.

5. Grid connection flexibility: lower output makes the grid connection simpler for remote regions, islands, and some developing countries, which have a limited electrical grid.

6. Gain efficiency: lower output and higher safety aspects, in comparison to large-scale NPPs, raise the straightforwardness of the SMR integration to other industries and applications such as seawater desalination and hydrogen production technologies.

7. Non-proliferation: considering the type of SMRs, the transport time and cost, as well as the radioactive materials, handling time can be reduced and longer refueling time may be achieved, depending on the designed fuel enrichment level.

8. Global market: innovative ideas and solutions provide circumstances that lead to opening a new market of the nuclear industry.

9. Cost reduction through learning: the experience achieved by building and installing multiple reactors in the SMR framework may reduce the cost of future deployments. 
Table 1. List of small modular reactors (SMRs) with their major design features and status.

\begin{tabular}{|c|c|c|c|c|c|c|}
\hline Output $\mathrm{MW}_{\mathrm{e}}$ & Reactor Model & Type & Power $\mathrm{MW}_{\mathrm{e}}$ & Developer, Country & $\begin{array}{l}\text { Primary } \\
\text { Circuit }\end{array}$ & Status \\
\hline \multirow{6}{*}{$<50$} & $4 S$ & LMFR $^{1}$ & 10 & Toshiba Corporation, Japan & Forced & Detailed design \\
\hline & CAREM & $\mathrm{PWR}^{2}$ & 30 & CNEA, Argentina & Natural & Under construction \\
\hline & KLT-40S & FNPP ${ }^{3}$-PWR & 35 & OKBM, Russia & Forced & In operation \\
\hline & RITM-200M & $\mathrm{IPWR}^{4}$ & 50 & OKBM, Russia & Forced & Near-term deployment \\
\hline & NuScale & IPWR & 50 & NuScale Power, USA & Natural & Under development \\
\hline & MCSFR & $\operatorname{MSR}^{5}$ & 50 & Elysium Industries, USA \& Canada & Forced & Conceptual design \\
\hline \multirow{4}{*}{$51-100$} & ACPR50S & $\begin{array}{c}\text { PWR } \\
\text { (marine-based) }\end{array}$ & 60 & CGNPC, China & Forced & Under construction \\
\hline & ACP100 & PWR & 100 & CNNC, China & Forced & Near-term deployment \\
\hline & SMART & PWR & 100 & KAERI, Korea & Forced & Near-term deployment \\
\hline & SVBR-100 & LMFR & 100 & JSC AKME Engineering, Russia & Forced & Detailed design \\
\hline \multirow{2}{*}{$101-150$} & CMSR & MSR & $100-115$ & Seaborg Technologies, Denmark & Forced & Conceptual design \\
\hline & SUPERSTAR & LMFR & 120 & Argonne National Laboratory, USA & Natural & Conceptual design \\
\hline \multirow{4}{*}{$151-200$} & SMR-160 & PWR & 160 & Holtec International, USA & Natural & Near-term deployment \\
\hline & PBMR-400 & HTGR $^{6}$ & 165 & PBMR SOC Ltd., South Africa & Forced & Preliminary Design \\
\hline & mPower & IPWR & 195 & BWX Technologies, USA & Forced & Under development \\
\hline & FUJI & MSR & 200 & ITMSF, Japan & Forced & Experimental Phase \\
\hline \multirow{5}{*}{$201-300$} & HTR-PM & HTGR & 210 & INET, Tsinghua University, China & Forced & Under construction \\
\hline & CAP200 & PWR & 220 & CGNPC, China & Forced & Conceptual design \\
\hline & Westinghouse SMR & PWR & 225 & Westinghouse, USA & Forced & Conceptual design completed \\
\hline & VK-300 & $\mathrm{BWR}^{7}$ & 250 & NIKIET, Russia & Natural & Detailed design \\
\hline & BREST-300 & LMFR & 300 & NIKIET, Russia & Forced & Near-term deployment \\
\hline
\end{tabular}

reactor, ${ }^{7}$ Boiling water reactor. 
SMRs require fewer financial resources in comparison to large-scale reactors, and are not usually considered to be economically competitive with large-scale reactors [32]. However, it may not be appropriate to consider only the economy of scale in comparing SMRs with common large-scale reactors, when the other features and parameters are not equal [33]. In some cases, the designed SMR pressure vessel with a height of about $20 \mathrm{~m}$ or more is not compact enough to reflect the sense of small size [7]. However, this drawback can be partly or completely solved by improving the suggested designs, and especially by making use of novel nuclear steam supply systems (NSSS), which occupies less space, keeping thermal-hydraulic conditions [34].

The interests of nuclear reactor developers is currently focused on the design and promotion of the integral SMR type, in which the components of the primary loop, such as the steam generator and pressurizer, are integrated into the reactor pressure vessel and containment vessel [29]. The coolant system of such a design is the main property that differs from the large-scale PWR, increasing the safety margins by eliminating or minimizing some potential accident factors. About eleven IPWRs of the SMR type have been introduced, and the majority of them are at the design and development stage and some of them are projected for near-term construction [7].

In coupling with the desalination plant, the use of SMR as the energy source can lead to several valuable advantages. The small size and high degree of modularity of the SMR make it easy to combine a nuclear power plant with a desalination plant. In particular, the design of the SMR allows each module to operate with membrane and/or thermal desalination technologies. The configuration of the integrated nuclear desalination plant can be set in such a way to provide the maximum flexibility in choosing a desalination technology, taking into account the requirements specific to the given plant. Considering the fact that the amount of heat available for desalination, in the case of SMR, is relatively lower than that for a large-scale reactor, it is highly advisable to evaluate thermodynamic analysis to approach the highest performance of the SMR and DP combination.

\section{Desalination Processes Coupling with SMR}

In order to attain the maximum efficiency of the nuclear desalination complex, it is significant to carefully analyze both the thermodynamic performance and the economic advantages of the nuclear desalination system for each suggested coupling scheme. Generally, the main purpose of such coupling as a cogeneration system is to effectively supply the energy-consuming plant, and at the same time, produce electricity with optimized efficiency of the cogeneration system. The amount of available heat and electricity in the case of a typical large-scale NPP is satisfactorily sufficient for supplying any large-capacity desalination (about some ten thousand cubic meters of freshwater production capacity per day), while in the case of SMR, the amount of heat available for non-electric applications is limited [35]. Theoretically, it may be possible to drive MSF or MED DPs of about 50,000 $\mathrm{m}^{3} /$ day using the energy generated by SMR, but in this case, the amount of power-loss ratio will be higher. Therefore, several cases of coupling schemes along with different standalone desalination processes (MED, MSF, RO) and HD technologies (RO+MED, RO+MSF) are assessed further, with the focus on HD technologies.

Implementation of the HD technologies can lead to considerable enhance in the efficiency of large-capacity desalination processes [5]. The quality of produced freshwater, which can be determined by considering the amount of total dissolved solids (TDS), can be improved by including thermal desalination units, and lower energy consumption can be achieved by participating membrane desalination systems. The stated potential advantages of HD systems convince developers to consider them as promising methods in the desalination industry. The reduction of the seawater intake volume can be achieved by using an HD method, in which brine of a standalone process is used as the feed water of other desalination methods. This feature, in addition to the lower environmental impacts, reduces the desalination cost in comparison to the freshwater price obtained by the standalone thermal desalination process. In many cases, the use of $\mathrm{RO}$ membranes for seawater desalination leads to the production of freshwater with a high amount of TDS (more than $300 \mathrm{mg} / \mathrm{L}$ ), which is not proper 
for drinking [36]. Mixing the obtained water by thermal desalination processes and RO membranes results in a proper amount of freshwater quality for drinking. Considering a constant desalination capacity, the hybridization can increase the membrane lifetime. The membrane efficiency can be increased by preheating feed water of the RO block using the relatively hot reject water of MED or MSF desalination units. Sharing some piping and post-treatment equipment in HD technology, the total cost of water production may be reduced. Regarding the NPP high-quality water requirements, the obtained freshwater by thermal processes with low TDS can be utilized. Since thermal desalination units generally are not easily affected by the high salinity and TDS of feed water, it is possible to partly or completely use the RO brine as the feed water for MED and MSF units.

In coupling a nuclear reactor to a desalination plant, it is very significant to take into account all the safety factors. In some cases, it is advisable to use additional safety measures employing an intermediate cycle between the hot stream of the nuclear reactor and thermal desalination systems. To decrease or completely remove the leakage probability of isotopes of radioactive elements from the nuclear power unit to the desalination plant, two possible designs are suggested. The first design is a "high-low-high pressure configuration", and the second design is a "low-high-low pressure configuration" [37]. The first configuration means that the intermediate circuit operates at a lower pressure than the main circuit of the nuclear power plant and the circuit that transfers heat to the desalination plant. In the second configuration, the pressure in the intermediate circuit is higher than in the other loops.

To improve the performance of the integrated nuclear desalination complex, three coupling schemes are considered in this study. By using these schemes, the benefits of HD technologies can be fully exploited. The first scheme is a typical nuclear desalination integration, in which the electricity and heat required for desalination are supplied by NPP (see Figure 1). The simplicity of the configuration is the main point of this scheme, where the required feed water for the thermal desalination unit and RO block are separately supplied. For any HD system of the first scheme, the brine of each method is not used as the feed water of other desalination processes.

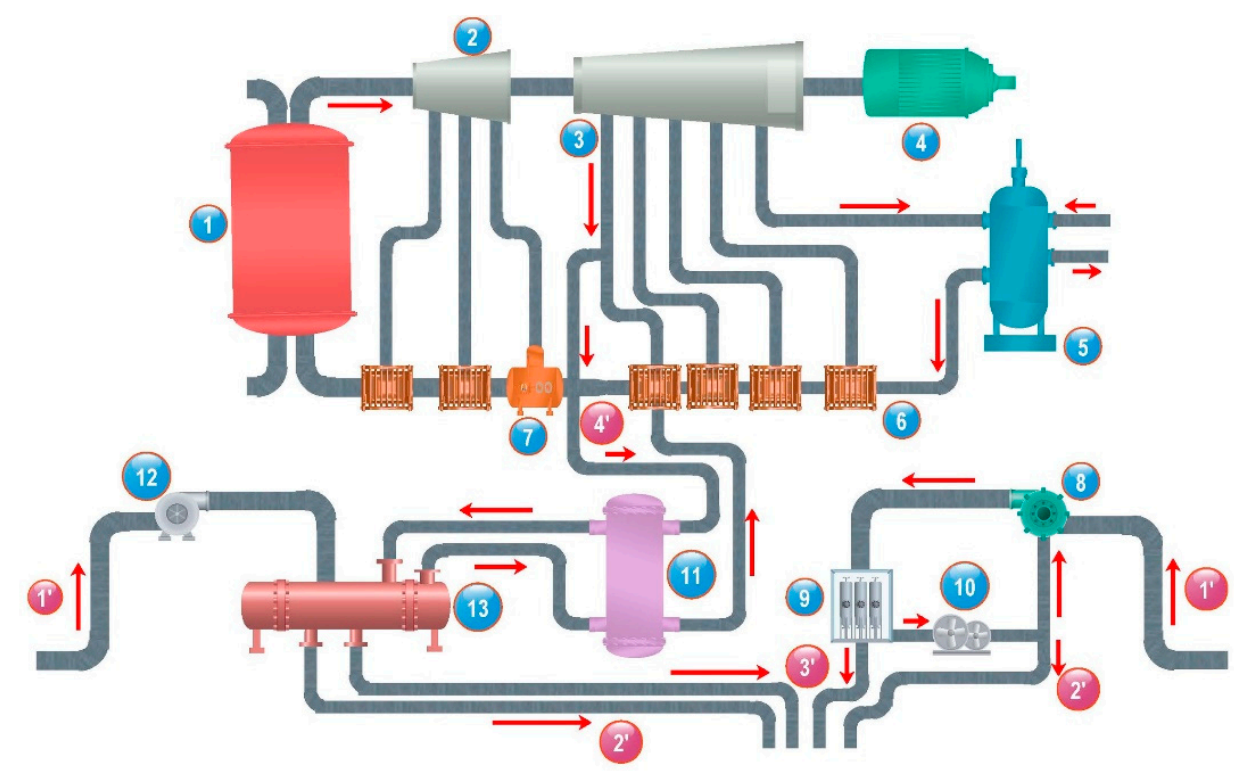

Figure 1. The first scheme of desalination plant (DP) coupling with SMR; 1 -steam generator, 2-high-pressure turbine, 3-low-pressure turbine, 4-generator, 5-condenser of the nuclear power plant (NPP), 6-preheater, 7-deaerator, 8-high-pressure pump, 9-membrane modules, 10-energy recovery system of the reverse osmosis (RO) plant, 11-intermediate heat-exchanger, 12-intake water pump, 13-thermal DP, $1^{\prime}$ —seawater intake pipeline, 2' —rejected brine pipeline, $3^{\prime}$ —produced freshwater pipeline, $4^{\prime}$-steam extraction pipeline. 
The second scheme can be considered as a configuration, in which different desalination technologies are involved and the operational conditions of each unit can impress the other process. In Figure 2, the second coupling option is shown. The key point of this scheme is the possibility of partly or completely feeding the thermal desalination unit using brine generated by RO membranes. The main goal of this scheme is to reduce the total volume of intake water. This will reduce the required pumping power and therefore the cost of water production. The bypass valve is designed to adjust the volume flow rate of the feed water to the thermal desalination unit or supply the required feed water if the reverse osmosis membrane systems do not work for any reason.

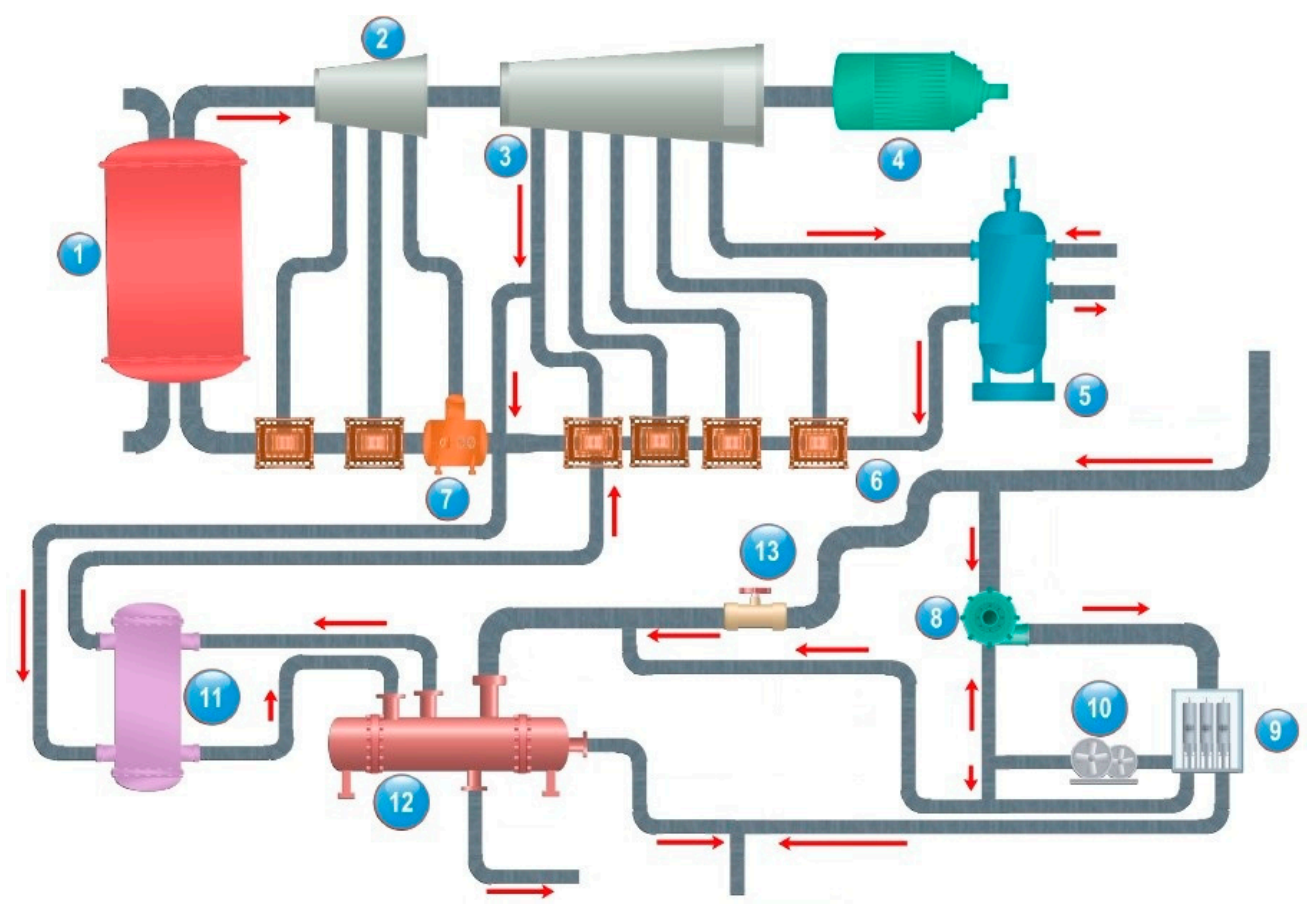

Figure 2. The second scheme of DP coupling with SMR; 1-steam generator, 2-high-pressure turbine, 3-low-pressure turbine, 4-generator, 5-condenser of the NPP, 6-preheater, 7-deaerator, 8-high-pressure pump, 9-membrane modules, 10-energy recovery system of RO plant, 11-intermediate heat-exchanger, 12-thermal DP, 13-bypass valve.

In the third suggested coupling scheme, the NPP condenser cooling water is used as feed water of DP. In this case, an increase in the feedwater temperature of RO membranes enhances their permeability, as a result of which, the RO plant recovery ratio usually increases by $1.5-3 \%$ per degree Celsius of temperature rise [5]. Making use of this configuration, the amount of feed water can be declined for constant freshwater production capacity in comparison to the other cases. Considering the fact that there is no need to supply DP directly by seawater intake equipment, a remarkable decrease in the pumping and piping costs may be achieved. A schematic view of the third HD coupling with the NPP is shown in Figure 3. 


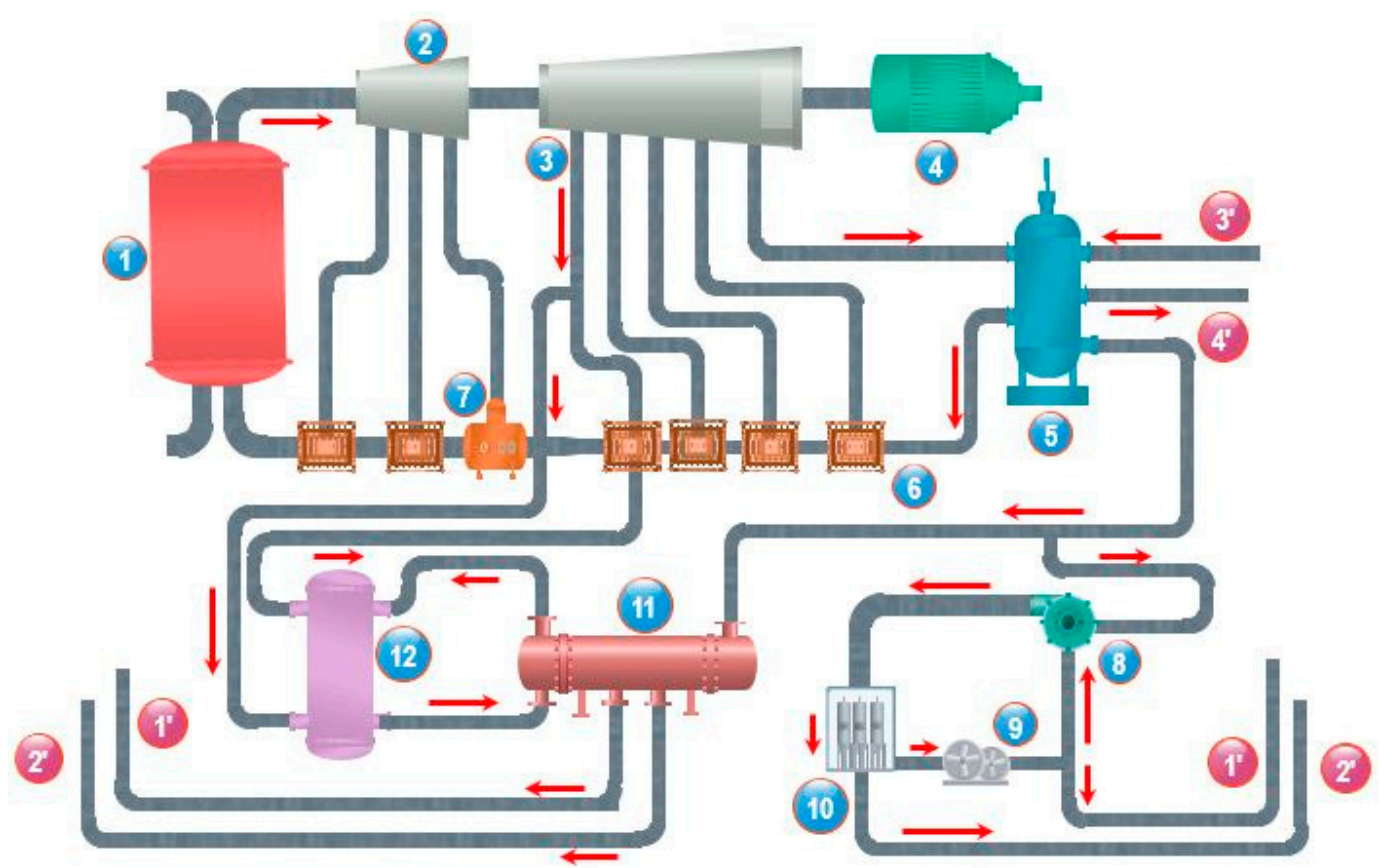

Figure 3. The third scheme of DP coupling with SMR; 1-steam generator, 2-high-pressure turbine, 3-low-pressure turbine, 4-generator, 5-condenser of the NPP, 6-preheater, 7-deaerator, 8-high-pressure pump, 9-energy recovery system of RO plant, 10-membrane modules, 11-thermal DP, 12 -intermediate heat-exchanger, $1^{\prime}$-rejected brine pipeline, $2^{\prime}$ - produced freshwater pipeline, $3^{\prime}$-inlet water to NPP's condenser, $4^{\prime}$ —outlet water from NPP's condenser.

To carry out the economic assessment of suggested schemes, a methodology based on the comprehensive simulation of the nuclear desalination systems [5] has been implemented. The most important economic parameters and formulations are briefly described here. In this method, the total desalinated water cost can be attained by dividing the total annual cost to the total annual volume of produced freshwater:

$$
\text { Total freshwater production cost }\left(\frac{\$}{\mathrm{~m}^{3}}\right)=\frac{\text { Total annual } \cos \mathrm{t}\left(\frac{\$}{\text { year }}\right)}{\text { Annual volume }\left(\frac{\mathrm{m}^{3}}{\text { year }}\right)} \text {. }
$$

in which the amount of total annual expense is given by:

Total annual cost

$$
\begin{aligned}
& =\text { Capital } \cos t s+\text { Elecricity } \cos t+\text { Heat } \cos t \\
& \text { +Operating and maintenance } \cos t
\end{aligned}
$$

Mainly, capital cost ( $\left.\mathrm{C}_{\mathrm{CAP}}\right)$ of DP comprises of construction cost, procurement, and engineering cost, which is directly influenced by the construction term. Particularly, ownership cost, base cost, contingency cost, and construction interest expense comprise the total capital expenses. In this definition, the total base cost $\left(\mathrm{C}_{\mathrm{B}}\right)$ can be obtained by summing the specific unit base cost $\left(\mathrm{C}_{\mathrm{SB}}\right)$, intermediate heat exchanger specific cost $\left(\mathrm{C}_{\mathrm{SIHX}}\right)$ - which is highly recommended to be installed in the case of MSF or MED integration to NPP-reserve heat source-specific cost ( $\mathrm{C}_{\mathrm{SRH}}$, for thermal DPs), and the specific seawater intake and outll costs $\left(\mathrm{C}_{\mathrm{SIO}}\right)$. It is worth mentioning that the specific unit base cost is a mean value, which mainly depends on the experience of DP construction, and other financial conditions of each country or region. As an instance, for some Middle East countries, the amounts of specific unit base costs for RO, MED, and MSF technologies are about 900, 1300, and $1400 \$ / \mathrm{m}^{3}$ day, respectively [20]. Total base expenses can be obtained using the following formula: 
The value of ownership expense can be determined by:

$$
\begin{gathered}
\mathrm{C}_{\mathrm{B}}=\left(\mathrm{C}_{\mathrm{SB}}+\mathrm{C}_{\mathrm{SIHX}}+\mathrm{C}_{\mathrm{SRH}}+\mathrm{C}_{\mathrm{SIO}}\right) \times \text { desalination volume per day } \\
\mathrm{C}_{\mathrm{OW}}=\mathrm{C}_{\mathrm{B}} \times \text { Ownership factor }
\end{gathered}
$$

Similarly, the contingency cost can be assumed to be a fraction of the total base and ownership costs, which is a case dependent parameter:

$$
\mathrm{C}_{\mathrm{CO}}=\left(\mathrm{C}_{\mathrm{B}}+\mathrm{C}_{\mathrm{OW}}\right) \times \text { Contingency factor }
$$

To obtain the value of interest during the construction, the following formula can be used:

$$
\mathrm{C}_{\mathrm{IDC}}=\left(\mathrm{C}_{\mathrm{CO}}+\mathrm{C}_{\mathrm{B}}+\mathrm{C}_{\mathrm{OW}}\right) \times\left((1+\mathrm{IR})^{\left(\frac{\mathrm{CD}}{24}\right)}-1\right)
$$

where IR is the amount of interest rate, CD is DP construction time.

In the case of MSF and MED desalination methods, it is appropriate to calculate the cost of heat, which is available in the form of hot steam from the NPP, where it could be used to generate electricity in the absence of cogeneration. For this purpose, the value of the gain output ratio (GOR), which is the desalinated water amount per $\mathrm{kg}$ of the consumed hot steam, should be calculated:

$$
\mathrm{GOR}_{\mathrm{MED}}=0.8 \times \frac{\left(\mathrm{T}_{\text {MaxB }}-\mathrm{T}_{\text {LastEff }}\right)}{\mathrm{T}_{\text {AvDiff }}}
$$

where $\mathrm{T}_{\mathrm{MaxB}}$ is the max brine temperature $\left({ }^{\circ} \mathrm{C}\right), \mathrm{T}_{\text {LastEff }}$ is the temperature at the last effect of MED unit $\left({ }^{\circ} \mathrm{C}\right), \mathrm{T}_{\mathrm{AvDiff}}$ is the average temperature difference between the effects of $\operatorname{MED}\left({ }^{\circ} \mathrm{C}\right)$. For the MSF method:

$$
\mathrm{GOR}_{\mathrm{MSF}}=\frac{\mathrm{H}\left[\mathrm{T}_{\text {Cond }}\right]}{\mathrm{HC}_{\mathrm{BH}} \times\left(\mathrm{T}_{\mathrm{ABH}}+\mathrm{T}_{\mathrm{TD}}\right)} \times\left(1-\exp \left(\frac{\mathrm{HC}_{\mathrm{B}} \times \mathrm{T}_{\mathrm{Op}}}{\mathrm{H}\left(\frac{\mathrm{T}_{\mathrm{MaxB}}+\mathrm{T}_{\text {Last }}}{2}\right)}\right)\right)
$$

where $\mathrm{H}\left(\mathrm{T}_{\mathrm{Cond}}\right)$ is latent heat $(\mathrm{kJ} / \mathrm{kg})$ at the condensation temperature, $\mathrm{HC}_{\mathrm{BH}}$ is the specific heat capacity of brine heater $\left(\mathrm{kJ} / \mathrm{kg}{ }^{\circ} \mathrm{C}\right), \mathrm{T}_{\mathrm{ABH}}$ represents the temperature of the heated water after brine heater $\left({ }^{\circ} \mathrm{C}\right)$, $\mathrm{T}_{\mathrm{TD}}$ is the average temperature drop between two MSF stages $\left({ }^{\circ} \mathrm{C}\right), \mathrm{H}_{\mathrm{CB}}$ is the average specific heat capacity of the brine $\left(\mathrm{kJ} / \mathrm{kg}{ }^{\circ} \mathrm{C}\right), \mathrm{T}_{\mathrm{Op}}$ is the operating temperature $\left({ }^{\circ} \mathrm{C}\right)$, and $\mathrm{T}_{\text {Lasts }}$ is the temperature at the last stage of MSF unit $\left({ }^{\circ} \mathrm{C}\right)$.

The amount of lost electricity $\mathrm{Q}_{\mathrm{L}}\left(\mathrm{MW}_{\mathrm{e}}\right)$ due to the steam extraction can be calculated using the following formula:

$$
\mathrm{Q}_{\mathrm{L}}=\mathrm{Q}_{\mathrm{A}} \times \eta_{\mathrm{C}} \times \eta_{\mathrm{LPT}} \times \eta_{\mathrm{G}} \times \eta_{\mathrm{T}}
$$

in which $Q_{A}$ is the available thermal power $(\mathrm{MW}), \eta_{C}$ is the efficiency of the Carnot cycle $(\%), \eta_{\mathrm{LPT}}$ is the isentropic efficiency of the low-pressure turbine $(\%), \eta_{\mathrm{G}}$ is the generator efficiency $(\%)$, and $\eta_{\mathrm{T}}$ is the turbine efficiency (\%).

Finally, heat cost $(\mathrm{k} \$)$ can be obtained by:

$$
\mathrm{C}_{\text {Heat }}=\mathrm{Q}_{\mathrm{L}} \times \mathrm{AV}_{\mathrm{DP}} \times 8760 \times \mathrm{C}_{\mathrm{LCE}}
$$

where $\mathrm{AV}_{\mathrm{DP}}$ represents the annual availability of the DP (\%) and $\mathrm{C}_{\mathrm{LCE}}$ is the levelized cost of electricity $(\$ / \mathrm{kWh})$.

An important component of desalinated water cost is the electricity cost, which is different for each desalination method. In the case of MED and MSF DPs, the amount of electricity consumption can be obtained by summing the specific electricity consumption of DP itself and the pumps of the 
intermediate loop. Therefore, the specific electrical energy consumption of MED and MSF units can be calculated using the following formulas:

$$
\mathrm{SE}_{\mathrm{MED}}=1.5+0.1\left(\mathrm{GOR}_{\mathrm{MED}}-10\right)+\frac{\mathrm{F}_{\mathrm{Int}} \times \eta_{\mathrm{EM}}}{9866 \times \eta_{\mathrm{IPE}}}
$$

and

$$
\mathrm{SE}_{\mathrm{MSF}}=2.7+0.2\left(\mathrm{GOR}_{\mathrm{MSF}}-8\right)+\frac{\mathrm{F}_{\mathrm{Int}} \times \eta_{\mathrm{EM}}}{9866 \times \eta_{\mathrm{IPE}}}
$$

where $F_{\text {Int }}$ is the water flow through the intermediate heat exchanger $\left(\mathrm{m}^{3} /\right.$ day $), \eta_{\mathrm{EM}}$ is the electric motor efficiency (\%), and $\eta_{I P E}$ is the intermediate loop pump efficiency. Using these values, the total electricity cost of a thermal DP $(\mathrm{k} \$)$ can be obtained by:

$$
\mathrm{EC}_{\text {thermal }}=8760 \times \mathrm{SE}_{\mathrm{MED} / \mathrm{MSF}} \times \mathrm{AV}_{\mathrm{DP}} \times \mathrm{C}_{\mathrm{LCE}}
$$

In the case of RO desalination technology, considering the absence of thermal energy, it is more straightforward to obtain the desalinated water cost. The value of electricity required for driving an RO desalination unit is comprised of the following components:

$$
\mathrm{E}_{\mathrm{RO}}=\mathrm{E}_{\mathrm{HPP}}+\mathrm{E}_{\mathrm{SWP}}+\mathrm{E}_{\mathrm{BP}}+\mathrm{E}_{\mathrm{OEC}}
$$

where $\mathrm{E}_{\mathrm{HPP}}$ is the electricity consumption of the high-pressure pumps (MW), $\mathrm{E}_{\mathrm{SWP}}$ shows the value of seawater pump consumption (MW), $\mathrm{E}_{\mathrm{BP}}$ is the booster pump electricity consumption (MW), and $\mathrm{E}_{\mathrm{OEC}}$ is other electricity consumption (MW). The total cost of the electricity consumption by RO block can be obtained by the following expression:

$$
\mathrm{EC}_{\mathrm{RO}}=\mathrm{E}_{\mathrm{RO}} \times \mathrm{AV}_{\mathrm{DP}} \times \mathrm{C}_{\mathrm{LCE}} \times 8760
$$

In the case of the HD system, desalination cost $\left(\$ / \mathrm{m}^{3}\right)$ can be determined by:

$$
\begin{array}{r}
\mathrm{C}_{\mathrm{HD}}=\left(\text { desalination cos t by MSF or MED } \times \mathrm{R}_{\mathrm{Th}}\right) \\
+\left(\text { desalination cos } \mathrm{t} \text { by } \mathrm{RO} \times \mathrm{R}_{\mathrm{RO}}\right)
\end{array}
$$

where $R_{T h}$ and $R_{R O}$ are the ratios of thermal and $R O$ desalination capacities to total DP capacity, respectively.

As has been stated in the previous sections, the recently developed computer program TEAND [5] is used for economic assessment. To give a better description of the calculation methodology, a comprehensive pattern is demonstrated in Figure 4. Accordingly, the initial step is the input data analyzation, which is defined by the user. The function of techno-economic analysis is performed by implementing five main blocks, which calculate the cost of freshwater based on MED, MSF, RO, and HD technologies with different coupling schemes. 


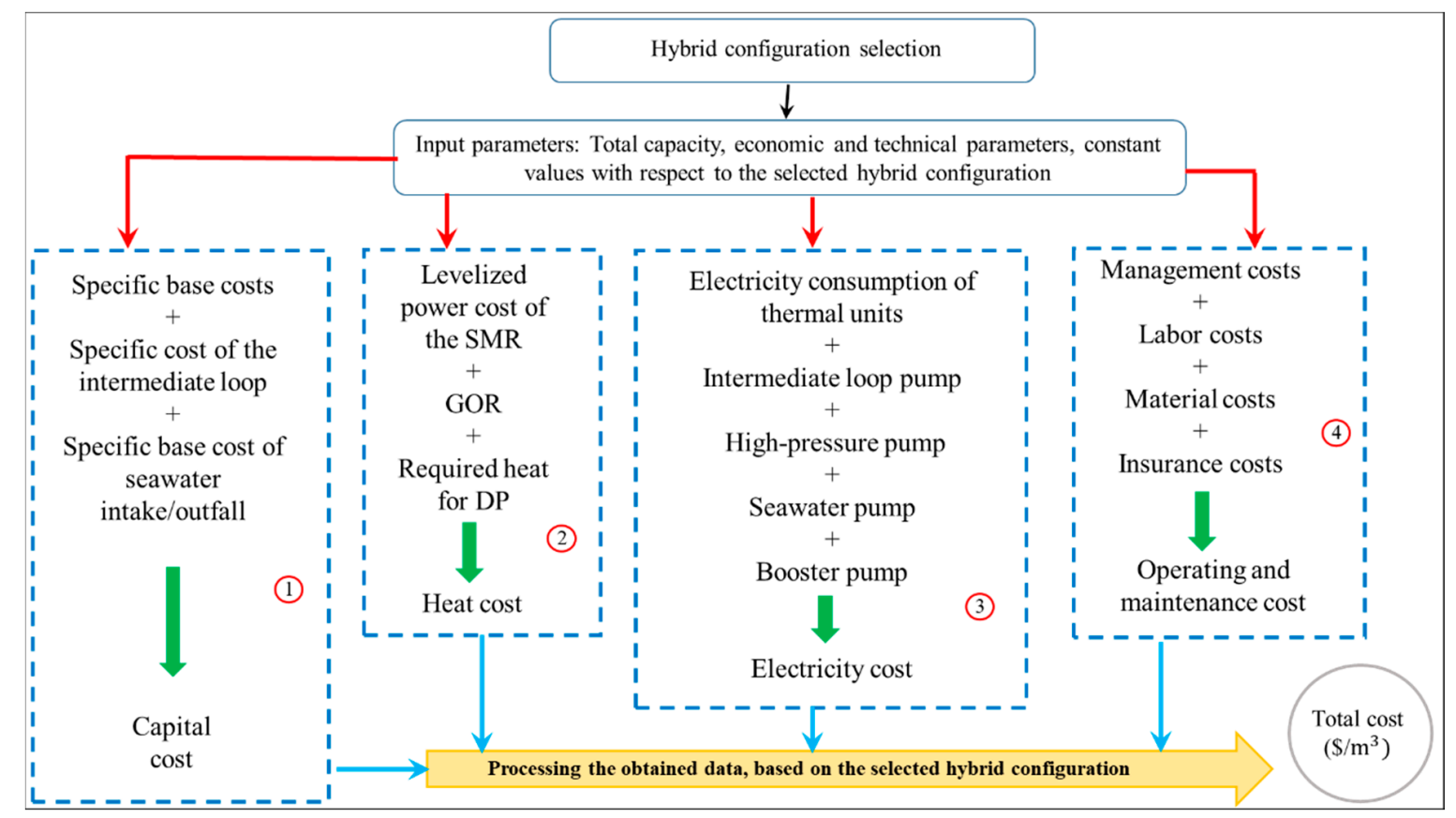

Figure 4. Flowchart of used calculation methodology.

\section{Results}

In order to perform a thermodynamic analysis of the SMR coupling with different desalination technologies, the IAEA Desalination Thermodynamic Optimization Program (DE-TOP) has been used, which has been proved and developed through the years for carrying out the thermodynamic analysis [27]. The software has the capability of analyzing thermodynamic parameters of the power generating system (here, SMR) integration to DPs as a cogeneration system, in which several configurations of heat extraction from SMR can be modeled. After entering the system characteristics and choosing the possible extraction and coupling options, the software calculates some useful parameters, such as the thermal utilization factor of the dual-purpose system, the amount of electricity loss due to the cogeneration, the required energy for desalination, and the heat loss ratio. However, it should be mentioned that it is not practically possible to extract any amount of hot stream from any point of the second loop, which should be taken into account if the purpose is to simulate a system that is applicable within the real (or close to real) conditions.

The secondary loop of the water-cooled NPP can be modeled using the DE-TOP software, according to fundamental thermodynamic models. The thermodynamic model has been formulated with the input parameters such as the NPP thermal capacity, pressure, and temperature of the live steam, condensing steam pressure, operational conditions of the preheaters, cooling water temperature, and the efficiency of equipment to evaluate the regenerative Rankine cycle with reheat. The input data are used by the software to simulate the power plant's thermodynamic model through solving all mass and energy flows and using a built-in databank of thermophysical properties, such as temperature, pressure, specific entropy, and enthalpy. In this model, a part of the expanded steam in the high-pressure turbine is delivered to feed the high-pressure heaters and deaerator. The remaining steam, after removing moisture content in moisture separator, is superheated by a portion of live steam and directed to the low-pressure turbine stages. The working steam passes through the condenser and condensate is directed to the low-pressure preheaters and deaerator. Afterwards, the main feedwater pumps deliver water to the steam generator through the high-pressure heaters. Steam can be extracted from the second cycle to be used for desalination processes by considering additional safety measures via an intermediate loop. Once the steam has released its latent heat, the condensed flow returns to the power plant in a proper location of the second loop. It is important to notice that before selecting 
the steam extraction point (or points) the amount of available steam and the temperature should be checked to make sure that the extracted steam has the potential of being used for driving MSF or MED units with the determined desalination capacities. Another point is to consider an additional temperature drop, due to the intermediate loop.

In this study, considering the simplicity and huge global experience in constructing and operating the light water reactors, an SMR of the PWR type is used as the energy-generating plant. Since the economic conditions of each country or region have a strong effect on the results of economic analysis, here, Iran is considered as the case study of coupling SMR to HD systems. The electricity output of the stand-alone SMR is assumed to be $100 \mathrm{MW}$. Three options are considered for extracting steam to supply the required heat energy of thermal desalination plants:

(a) High-pressure steam after the steam generator;

(b) Medium pressure bleed steam of the high-pressure turbine;

(c) Bleed steam from both low- and high-pressure turbines.

In order to make sure that the amount of hot steam generated by SMR is sufficient for considered desalination capacity, in option c, hot steam is extracted from both low- and high-pressure turbines. The results of the thermodynamic analysis of the SMR combination with a thermal desalination plant with a capacity of $15,000 \mathrm{~m}^{3} /$ day are given in Table 2 . Desalination energy is minimized by using option $\mathrm{c}$ in an SMR combination with MED technology. The extraction of steam after the steam generator (option a) results in a large amount of power loss, because the temperature and pressure of the steam after the steam generator is too high, and it is better to use it to drive a high-pressure turbine for electricity generation. The combination of a desalination plant with SMR leads to an increase in the thermal utilization factor of the cogeneration plant by about $6-9 \%$ in the considered options.

Table 2. The results of the thermodynamic analysis for various coupling configurations.

\begin{tabular}{ccccccc}
\hline \multirow{2}{*}{ Parameter } & \multicolumn{7}{c}{ Options } \\
\cline { 2 - 7 } & $\mathbf{a}$ & $\mathbf{b}$ & $\mathbf{c}$ & $\mathbf{a}$ & $\mathbf{b}$ & $\mathbf{c}$ \\
\hline Desalination technology & MED & MED & MED & MSF & MSF & MSF \\
Thermal utilization factor, $\%$ & 40.7 & 41.9 & 42.7 & 41.8 & 43.2 & 43.6 \\
Electricity output, MW & 86.7 & 90.9 & 93.7 & 84.3 & 89.3 & 90.5 \\
Power loss ratio, $\%$ & 37.6 & 25.9 & 18 & 37.6 & 25.9 & 23 \\
Energy to desalination, MW & 16.1 & 11.9 & 9.1 & 20.6 & 15.7 & 14.5 \\
\hline
\end{tabular}

The dependence of the cogeneration complex electricity output on the capacity of the desalination plant for various options is shown in Figure 5. Implementing the MSF method leads to higher amounts of electricity and heat consumption, which means the less electricity output of the cogeneration plant. Among the suggested steam extraction options, the utilization of option $\mathrm{c}$ is the most proper one, however, due to the high energy consumption of MSF, option b with MED DP leads to higher electricity output of the complex than MSF DP with option c. Using option a, the consumption of high-temperature steam is sufficient to produce a large amount of freshwater by the thermal desalination processes (about $80,000 \mathrm{~m}^{3} /$ day), however, the value of power loss will be large. This case can be suggested if the SMR (or one module of SMR) is designed only for desalination purposes. The best option for generating a higher amount of electricity is to extract steam from a low-pressure turbine for supplying MED technology. 


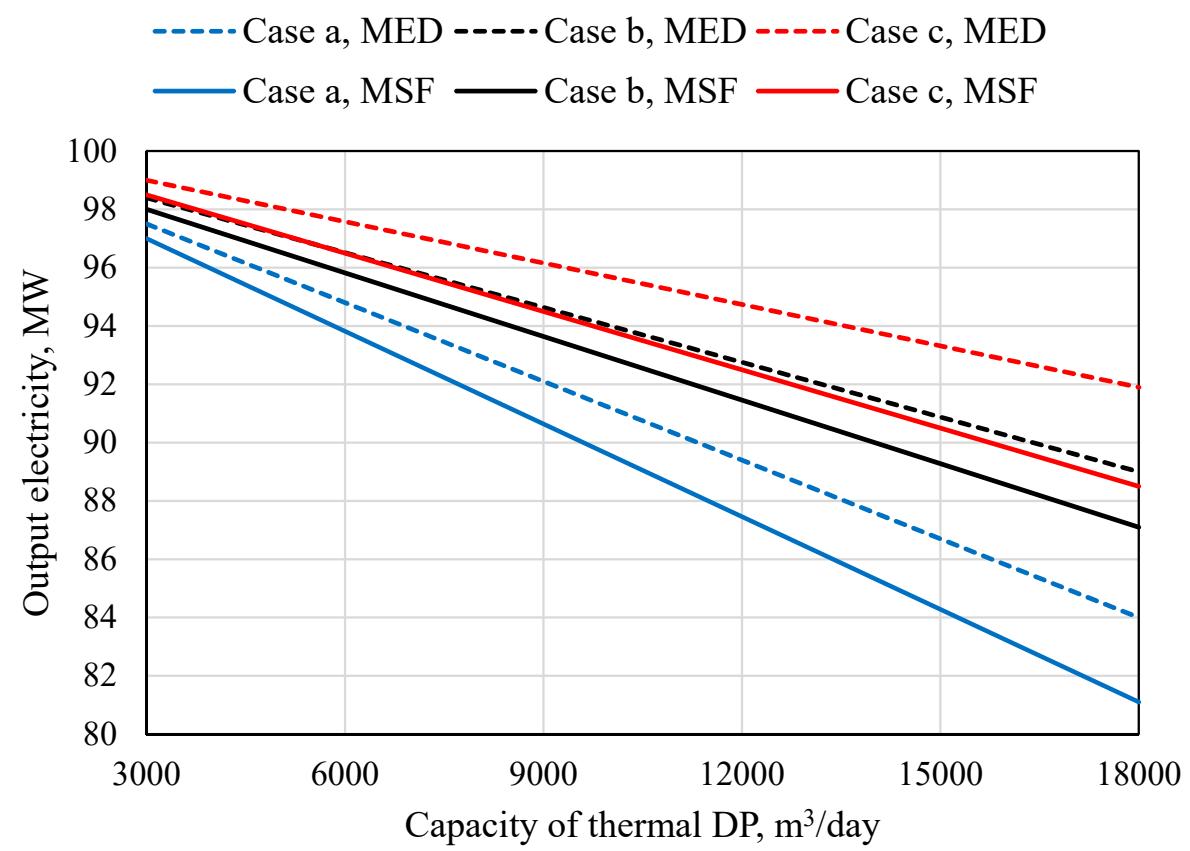

Figure 5. Variation of the electricity produced by the cogeneration system for different desalination capacities.

In Figure 6, the final freshwater production costs by different HD methods are illustrated. In this case, the total desalination capacity varies from 10,000 to $60,000 \mathrm{~m}^{3} /$ day, with a hybridization degree of $30 \%$. In HD systems, the hybridization degree can be defined as the ratio of thermal to total desalination capacity. The freshwater production cost for all options changes more intensively within the capacity of about 10,000 to 20,000 $\mathrm{m}^{3} /$ day, in comparison to higher production capacities. In both MSF and MED technologies, the use of $\mathrm{RO}$ brine as the feed water for the thermal desalination unit slightly reduces the desalination cost. The utilization of NPP condenser water leads to a considerable reduction in desalination cost by means of HD systems, where the cost of desalinated water at maximum capacity decreases by $6.4 \%$ and $7.6 \%$ for RO+MSF and RO+MED cases, respectively.

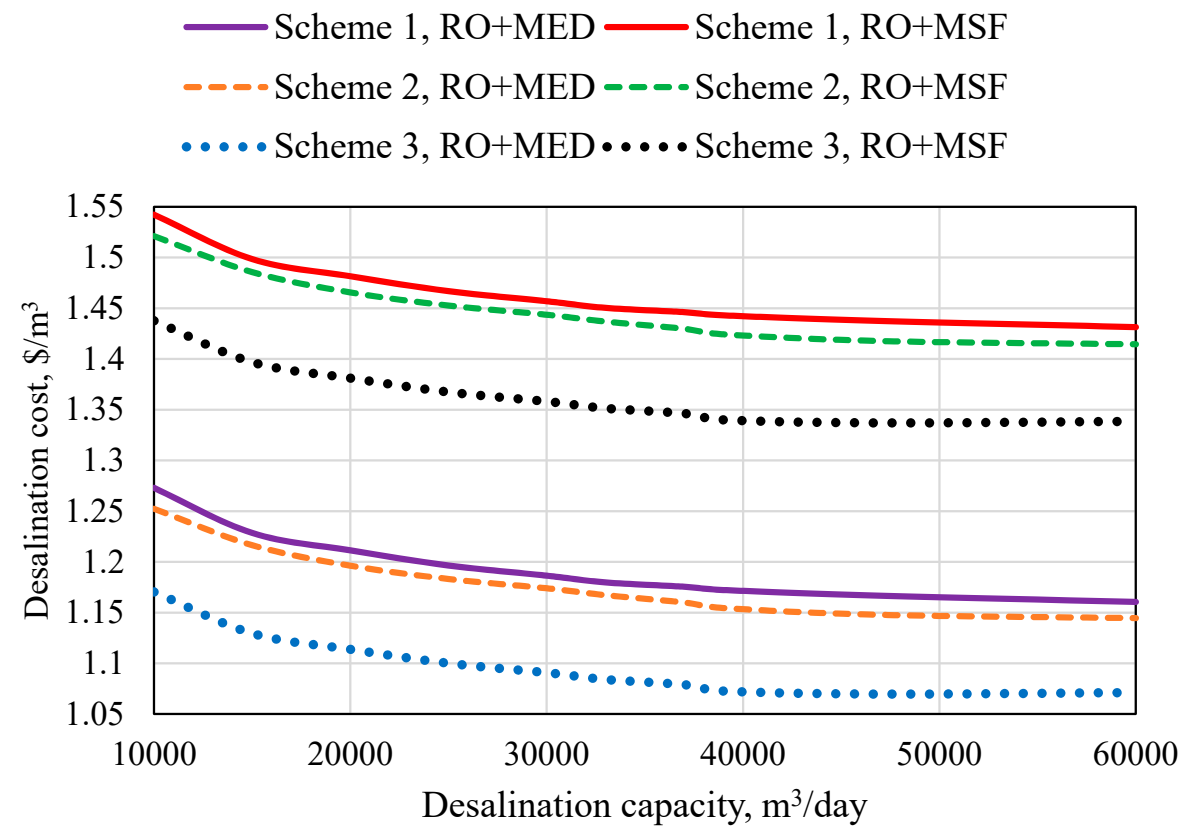

Figure 6. Desalination cost for suggested cases of hybrid desalination (HD) technologies in different capacities. 
To give a better insight into the advantages of using RO brine to supply the required feed water thermal DP, the costs of water intake and pretreatment for the second hybrid scheme and a typical hybrid system are expressed in Figure 7. In this case, a capacity of $60,000 \mathrm{~m}^{3} /$ day is considered for different hybridization degrees (from 20 to $80 \%$ ). It is obvious from the figure that a considerable saving in the water intake and pretreatment cost can be gained by using the second suggested hybrid scheme. By increasing the share of freshwater production of thermal DP, at the hybridization degree of about $41 \%$, the amount of RO brine is not sufficient to completely supply thermal DP, hence, the rest of the required feed water is supplied by a reservoir tank or from the sea. At this hybridization degree, an economic efficiency of about $3.52 \mathrm{M} \$$ can be gained using the suggested HD scheme.

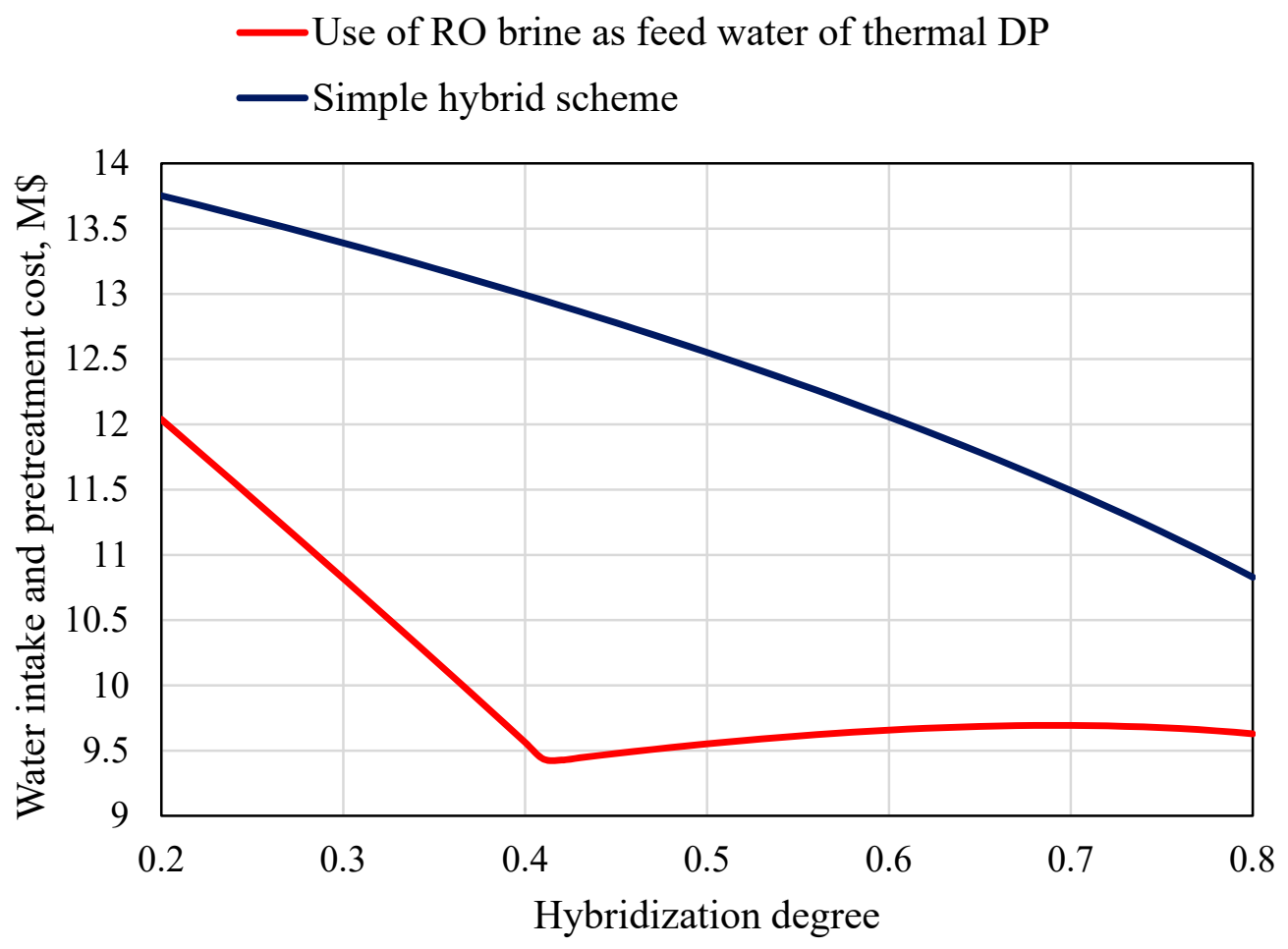

Figure 7. Water intake and pretreatment costs for different hybridization degrees.

An increase in the $\mathrm{RO}$ membrane feedwater temperature leads to viscosity reduction of the saline water, in the result of which permeability of the RO membranes enhances, and the recovery ratio increases. On the other hand, this phenomenon decreases the produced freshwater quality (increases TDS). Desalinated water by thermal (low TDS) and membrane (high TDS) technologies can be mixed, to result in a standard amount of TDS for drinking water, which is no more than $300 \mathrm{ppm}$ [36]. Therefore, in the third suggested scheme, it is vital to determine the hybridization degree, which is required to produce freshwater suitable for drinking. For this purpose, the proper amounts of hybridization degree for different $\mathrm{RO}$ membrane feed water temperatures along with the calculated freshwater costs for the capacity of $60,000 \mathrm{~m}^{3} /$ day are given in Figure 8 . As feedwater temperature increases up to $29^{\circ} \mathrm{C}$, desalination cost decreases. At $30^{\circ} \mathrm{C}$ and higher temperatures, since TDS of the mixed desalinated water is higher than the standard value, an increase in the hybridization degree is considered to keep the amount of TDS bellow the allowable value. As a result, the ratio of freshwater produced by the thermal desalination unit increases. 


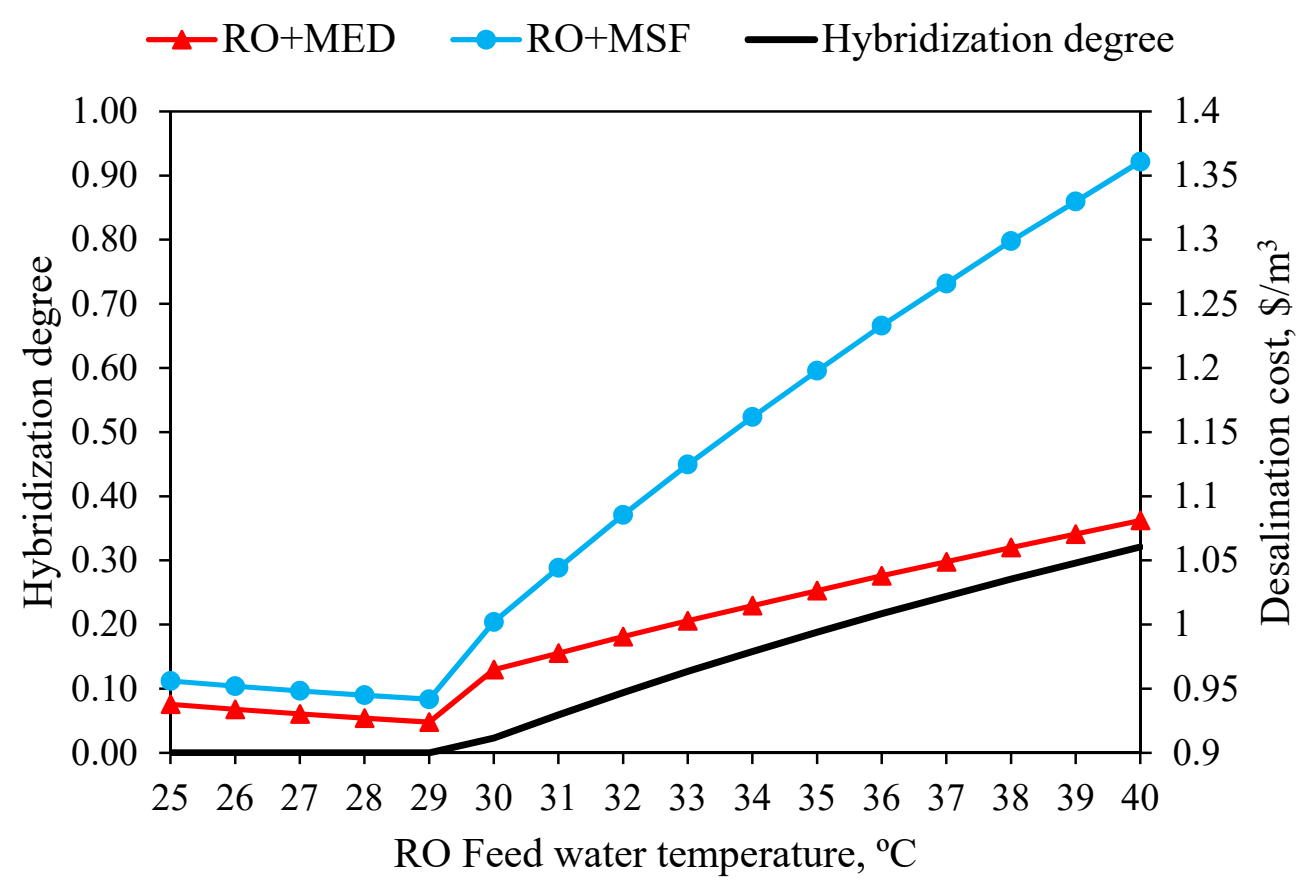

Figure 8. Desalination cost and proper hybridization degree for various temperatures.

\section{Conclusions}

Nowadays, there is a worldwide challenge for shifting from typical fossil fuel energy sources to low-carbon and safer energy sources. Among the many options, improving the latest generations of large-scale nuclear reactors via the SMR concept can be counted as an advantageous alternative that is already planned in many countries. On the other hand, regarding the physical shortage or scarcity of freshwater and the high energy-consuming desalination processes, the utilization of SMR coupled to DP can be considered a forward-looking way of supplying both electricity and energy for freshwater production in the medium-term future. In this regard, it is advisable to employ high-performance desalination techniques, such as HD technologies, to maximize the performance of the cogeneration plant.

In this study, a thermo-economic analysis of integrating an SMR to HD systems has been carried out. One of the main purposes of this work is to show that, instead of stand-alone desalination processes, the participation of both thermal and membrane desalination methods can increase the productivity of the integrated system. Several HD schemes have been suggested to be coupled with SMR with different steam extraction points. As the best option for cogeneration plants, steam from the low-pressure turbine can be extracted to supply HD plants, where a part of the relatively hot water of the SMR condenser is used as feed water of DP. The use of this configuration decreases the environmental impacts, in which there is no need to pump additional seawater for feeding DP. On the other hand, a raise in the feedwater temperature increases the recovery ratio of the RO membranes. From an economic point of view, utilization of the suggested configuration leads to a considerable cost reduction of about $6.4 \%$ and $7.6 \%$ with RO+MSF and RO+MED HD systems, respectively. The results of the economic analysis are provided for the case study of Iran, however, the described method and suggested schemes are advisable for other arid and semi-arid regions, such as Mexico, Saudi Arabia, and Australia, where the similar results can be expected. To reduce the uncertainties of the cost determination and obtain more precise results, it is desirable to evaluate the data uncertainty for different cases. Further studies can aim to take the advantages of both renewable and nuclear energy sources as a hybrid nuclear-renewable energy system coupled to HD technologies in various regions. 
Author Contributions: Conceptualization, S.H.G. and K.S.; formal analysis, E.S., E.F. and A.S.; funding acquisition, K.S. and E.F.; investigation, S.H.G.; methodology, S.H.G. and K.S.; project administration, S.H.G. and E.F.; resources, E.S. and A.S.; software, E.S.; supervision, E.F. and A.S.; validation, E.S. and A.S.; writing-original draft, S.H.G. and K.S. All authors have read and agreed to the published version of the manuscript.

Funding: This research was funded by Academic Excellence Project 5-100 proposed by Peter the Great St. Petersburg Polytechnic University.

Conflicts of Interest: The authors declare no conflict of interest.

\section{References}

1. Youssef, P.G.; Al-Dadah, R.K.; Mahmoud, S.M. Comparative Analysis of Desalination Technologies. Energy Procedia 2014, 61, 2604-2607. [CrossRef]

2. Nassrullah, H.; Anis, S.F.; Hashaikeh, R.; Hilal, N. Energy for Desalination: A State-Of-The-Art Review. Desalination 2020, 491, 114569.

3. Al-Karaghouli, A.; Kazmerski, L.L. Energy Consumption and Water Production Cost of Conventional and Renewable-Energy-Powered Desalination Processes. Renew. Sustain. Energy Rev. 2013, 24, 343-356. [CrossRef]

4. Walsh, B.P.; Murray, S.N.; O'Sullivan, D.T.J. The Water Energy Nexus, an ISO50001 Water Case Study and the Need for a Water Value System. Water Resour. Ind. 2015, 10, 15-28. [CrossRef]

5. Sadeghi, K.; Ghazaie, S.H.; Sokolova, E.; Fedorovich, E.; Shirani, A. Comprehensive Techno-Economic Analysis of Integrated Nuclear Power Plant Equipped with Various Hybrid Desalination Systems. Desalination 2020, 493, 114623. [CrossRef]

6. NEA/OECD. Small Modular Reactors: Nuclear Energy Market Potential for Near Term Deployment. 2016. Available online: https://www.oecd-nea.org/ndd/pubs/2016/7213-smrs.pdf (accessed on 3 August 2020).

7. IAEA. Advances in Small Modular Reactor Technology Developments. Available online: https://aris.iaea. org/Publications/SMR-Book_2018.pdf (accessed on 3 August 2020).

8. Volk, R.; Hübner, F.; Hünlich, T.; Schultmann, F. The Future of Nuclear Decommissioning-A Worldwide Market Potential Study. Energy Policy 2019, 124, 226-261. [CrossRef]

9. Corsini, A.; Tortora, E. Sea-Water Desalination for Load Levelling of Gen-Sets in Small Off-Grid Islands. Energies 2018, 11, 2068. [CrossRef]

10. Wang, Z.; Lin, X.; Tong, N.; Li, Z.; Sun, S.; Liu, C. Optimal Planning of a 100\% Renewable Energy Island Supply System Based on the Integration of a Concentrating Solar Power Plant and Desalination Units. Int. J. Electr. Power Energy Syst. 2020, 117, 105707. [CrossRef]

11. Abdelkareem, M.A.; El Haj Assad, M.; Sayed, E.T.; Soudan, B. Recent Progress in the Use of Renewable Energy Sources to Power Water Desalination Plants. Desalination 2018, 435, 97-113. [CrossRef]

12. Ghazaie, S.H.; Sadeghi, K.; Sokolova, E.; Fedorovich, E.; Makhuhin, S. Assessment of the Integrated Nuclear Plant for Electricity Production and Seawater Desalination in Iran. Desalin. Water Treat. 2020, 188, $20-30$.

13. Sadeghi, K.; Ghazaie, S.H.; Sokolova, E.; Fedorovich, E.; Shirani, A. Thermo-Economic Assessment of the Possible Desalination Processes for the Second Block of Bushehr Nuclear Power Plant. E3S Web Conf. 2019, 140, 03001. [CrossRef]

14. Misra, B.M. Seawater Desalination Using Nuclear Heat/Electricity-Prospects and Challenges. Desalination 2007, 205, 269-278. [CrossRef]

15. Jung, Y.H.; Jeong, Y.H.; Choi, J.; Wibisono, A.F.; Lee, J.I.; No, H.C. Feasibility Study of a Small-Sized Nuclear Heat-Only Plant Dedicated to Desalination in the UAE. Desalination 2014, 337, 83-97. [CrossRef]

16. Khan, S.U.D.; Khan, S.U.D.; Haider, S.; El-Leathy, A.; Rana, U.A.; Danish, S.N.; Ullah, R. Development and Techno-Economic Analysis of Small Modular Nuclear Reactor and Desalination System Across Middle East and North Africa Region. Desalination 2017, 406, 51-59. [CrossRef]

17. Al-Othman, A.; Darwish, N.N.; Qasim, M.; Tawalbeh, M.; Darwish, N.A.; Hilal, N. Nuclear Desalination: A State-Of-The-Art Review. Desalination 2019, 457, 39-61. [CrossRef]

18. Mantero, G.; Lomonaco, G.; Marotta, R. Nuclear Desalination: An Alternative Solution to the Water Shortage. Glob. J. Energy Technol. Res. Updates 2015, 1, 57-70.

19. Ghazaie, S.H.; Sadeghi, K.; Sokolova, E.; Fedorovich, E.; Shirani, A. Nuclear Desalination in Iran, Current Status and Perspectives. E3S Web Conf. 2019, 140, 04001. [CrossRef] 
20. Sadeghi, K.; Ghazaie, S.H.; Fedorovich, E.D.; Sokolova, E.A.; Shirani, A.S. Economic Assessment of the Possible Desalination Processes for the First Unit of Bushehr Nuclear Power Plant. Therm. Eng. 2020, 67, 271-281.

21. Khalid, F.; Dincer, I.; Rosen, M.A. Comparative Assessment of CANDU 6 and Sodium-Cooled Fast Reactors for Nuclear Desalination. Desalination 2016, 379, 182-192. [CrossRef]

22. Ng, K.C.; Shahzad, M.W.; Son, H.S.; Hamed, O.A. An Exergy Approach to Efficiency Evaluation of Desalination. Appl. Phys. Lett. 2017, 110, 184101. [CrossRef]

23. Khan, S.U.; Khan, S.U. Karachi Nuclear Power Plant (KANUPP): As Case Study for Techno-Economic Assessment of Nuclear Power Coupled with Water Desalination. Energy 2017, 127, 372-380. [CrossRef]

24. Shahzad, M.W.; Burhan, M.; Ng, K.C. A Standard Primary Energy Approach for Comparing Desalination Processes. NPJ Clean Water 2019, 2, 1. [CrossRef]

25. Genco, F.; Genco, G. Nuclear Desalination in Chile: A Competitive Solution. Desalin. Water Treat. 2019, 140, 24-34. [CrossRef]

26. Shahzad, M.W.; Burhan, M.; Ng, K.C. Pushing Desalination Recovery to the Maximum Limit: Membrane and Thermal Processes Integration. Desalination 2017, 416, 54-64. [CrossRef]

27. Sánchez-Cervera, I.G.; Kavvadias, K.C.; Khamis, I. DE-TOP: A New IAEA Tool for the Thermodynamic Evaluation of Nuclear Desalination. Desalination 2013, 321, 103-109. [CrossRef]

28. Locatelli, G.; Fiordaliso, A.; Boarin, S.; Ricotti, M.E. Cogeneration: An Option to Facilitate Load Following in Small Modular Reactors. Prog. Nucl. Energy 2017, 97, 153-161. [CrossRef]

29. Zeliang, C.; Mi, Y.; Tokuhiro, A.; Lu, L.; Rezvoi, A. Integral PWR-Type Small Modular Reactor Developmental Status, Design Characteristics and Passive Features: A Review. Energies 2020, 13, 2898. [CrossRef]

30. Nian, V. The Prospects of Small Modular Reactors in Southeast Asia. Prog. Nucl. Energy 2017, 98, 131-142. [CrossRef]

31. Teräsvirta, A.; Syri, S.; Hiltunen, P. Small Nuclear Reactor-Nordic District Heating Case Study. Energies 2020, 13, 3782. [CrossRef]

32. Locatelli, G.; Bingham, C.; Mancini, M. Small Modular Reactors: A Comprehensive Overview of Their Economics and Strategic Aspects. Prog. Nucl. Energy 2014, 73, 75-85. [CrossRef]

33. Mignacca, B.; Locatelli, G. Economics and Finance of Small Modular Reactors: A Systematic Review and Research Agenda. Renew. Sustain. Energy Rev. 2020, 118, 109519. [CrossRef]

34. Ilyas, M.; Aydogan, F. Steam Generator Performance Improvements for Integral Small Modular Reactors. Nucl. Eng. Technol. 2017, 49, 1669-1679. [CrossRef]

35. IAEA. Optimization of the Coupling of Nuclear Reactors and Desalination Systems. Available online: https://www-pub.iaea.org/MTCD/Publications/PDF/te_1444_web.pdf (accessed on 3 August 2020).

36. Al-hotmani, O.M.A.; Al-Obaidi, M.A.; Patel, R.; Mujtaba, I.M. Performance Analysis of a Hybrid System of Multi Effect Distillation and Permeate Reprocessing Reverse Osmosis Processes for Seawater Desalination. Desalination 2019, 470, 114066. [CrossRef]

37. Bouaichaoui, Y.; Belkaid, A.; Amzert, S.A. Economic and Safety Aspects in Nuclear Seawater Desalination. Procedia Eng. 2012, 33, 146-154. [CrossRef]

(C) 2020 by the authors. Licensee MDPI, Basel, Switzerland. This article is an open access article distributed under the terms and conditions of the Creative Commons Attribution (CC BY) license (http://creativecommons.org/licenses/by/4.0/). 